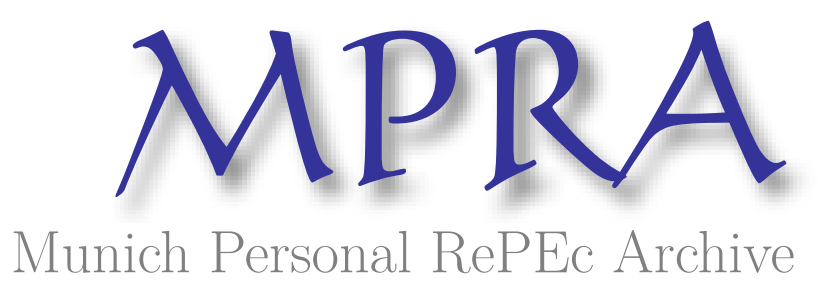

Accounting for the effect of exogenous non-Economic variables on natural gas demand in oil producing African countries

Ackah, Ishmael

Institute for Oil and Gas Studies, University of Cape Coast, Ghana

24 October 2015

Online at https://mpra.ub.uni-muenchen.de/81553/

MPRA Paper No. 81553, posted 09 Oct 2017 11:34 UTC 


\title{
Accounting for the effect of exogenous non-Economic variables on natural gas demand in oil producing African countries
}

\author{
Ishmael Ackah
}

Institute for Oil and Gas Studies, University of Cape Coast, Ghana. Email address: ackish85@yahoo.com; phone: +2332633687304

\begin{abstract}
With less than $50 \%$ of the population of Sub-Saharan Africa having access to modern forms of energy and the desire to minimize the impact of energy consumption on the environment, there is a need to invest in an energy source that is affordable, available and environmentally clean. Natural gas is therefore the preferred choice of energy since it has minimum impact on the environment among the fossil fuels and is relatively affordable. In this study, the generalized methods of moments (GMM), a dynamic panel two stage least squares and the general unrestricted model (GUM) through Autometrics ${ }^{T M}$ are employed to estimate the demand for natural gas in oil producing African countries. The GUM suggests that oil producing African countries have been consuming excessive natural gas that seems to offset improved technical efficiency of appliances. The study finds that both economic and technical factors are important drivers of natural gas consumption. In particular, output exerts a positive and significant influence on natural gas demand, whereas energy price and energy resource depletion have a negative and significant effect. It is recommended that energy efficiency measures should be implemented in these countries.
\end{abstract}

Key words: Natural gas demand, Energy, Autometrics, Oil producing African countries, Fossil fuels 


\section{Introduction}

The global need for clean and affordable sources of energy cannot be overemphasized, since the consumption of energy has been found to be a major determinant of $\mathrm{CO} 2$ emissions (Bhattacharya, 2010). Access to a clean, affordable and available source of energy has therefore become a major policy priority for both developed and developing economies. According to BP (2010), coal emits 94.6 ppm $\mathrm{CO}_{2}$ per each unit use. This notwithstanding, natural gas emits $70 \%$ less carbon than coal and $40 \%$ less than crude oil (BP, 2010). This makes natural gas the preferred fuel of choice for three reasons. First, natural gas is cheaper than petroleum and cleaner than both coal and petroleum (Aras and Aras, 2004). In addition, due to its efficiency and attractive qualities, natural gas is suitable for power generation. This means that, since Africa is a developing continent with a great economic potential, natural gas should be the fuel that drives this growth. However, only $5.4 \%$ of Africa's energy mix can be attributed to natural gas (IEA, 2013). Has Africa been left behind in the natural gas revolution? Second, the discovery of natural gas in Africa has been increasing over the last two decades. Finally, natural gas plays a vital role in reducing capital costs in energy intensive industries since natural gas using appliances like gas fired thermal plants are relatively cheaper to operate (Shahbaz et al., 2013). Natural gas therefore comes to mind as the preferred choice. Apergis and Payne (2010) note that most economies are using natural gas as a major source of energy and cite reduction in carbon emissions as the reason.

In a report in 2011, the IEA predicts that natural gas demand will grow in the coming decades due to five main factors. First, there is increasing use of natural gas in emerging and developing countries like China, Bangladesh and Turkey. Second, the use of natural gas in the transport sector has been increasing in both developed and developing countries. Thirdly due to the Fukushima Daiichi nuclear disaster, slower growth in nuclear power is anticipated. The fourth factor has been the discovery of conventional natural gas such as Tanzania, Mozambique and Ghana and the productivity of old gas fields. Lastly, there has been rapid expansion of global supply capacity for Liquefied Natural Gas (LNG). For instance, Nigeria, 
which hitherto flared its gas, became the 4th largest LNG exporter in 2012. Total (2011) estimates that the demand for natural gas will grow at $2.5 \%$ annually over the next two decades. This implies that natural gas will become the second most important fossil fuel after oil taking the growth rate of coal at $0.2 \%$ and crude oil at $1.1 \%$ over the same period.

These demand projections require investments in LNG facilities, pipelines and natural gas infrastructure. Since investment in natural gas infrastructure is huge and requires long lead times, knowledge of the determinants of natural gas can guide investment decisions. Again, natural gas is traded regionally in North American, European and Asia-Pacific gas markets. Nevertheless, Africa has no gas market. Given the complexity of the natural gas market, the interplay of factors that influence the market and the interdependence of these factors, a quantitative model representing the demand side of the market needs to be devised to guide energy policy decisions.

Shabbaz et al. (2013) review the literature on natural gas demand and highlight two important gaps. First, the results are not unanimous as some studies report bidirectional, unidirectional or no relation between natural gas demand and economic growth. Second, the estimation methods are less suitable in some studies especially those using a bivariate model which is subject to omitted variable bias. Third, most of the studies on natural gas are outdated and are not able to capture current trends in the energy sector. For instance, the global economic crisis and the recent development in the climate change agenda have drastically changed the fuel mix policy. Therefore, without the inclusion of this time period, results of previous studies may have little relevance for current natural gas policy making. The few studies on natural gas in Africa usually test the causal relation between economic growth and gas demand in a multivariate framework or in a bivariate framework which can potentially omit some relevant variables. According to Hunt and Evans (2011), understanding the factors that influence the demand for energy is vital to design an energy policy framework that deals with issues such as climate change, energy access, energy security and energy investments. To support this point, Bianco et al. (2014) posit that knowledge of natural gas demand helps to predict natural gas consumption with high accuracy, to optimally manage domestic production, manage gas supply contracts and develop local gas infrastructure. The objective of this study is to identify the determinants of natural gas demand in oil producing African countries. The study also seeks to determine the underlying energy demand trend (UEDT) of natural gas demand in oil producing African countries.

This study contributes to the existing literature on natural gas demand in three main ways. First, the study incorporates both heterogeneous and homogenous variance structures by 
employing a dynamic panel and a structural time series analysis. Second, contrary to studies on natural gas demand such as (Khan, 2015; Waheed and Martin, 2013), this study employs a multivariate framework that includes GDP, energy resource depletion, $\mathrm{CO} 2$, price and a stochastic trend that captures the effect of exogenous unobservable factors on natural gas consumption. Finally, in order to enhance the robustness of the findings and depart from existing time series applications to natural gas demand (see Ackah, 2014; Khan, 2015; Waheed and Martin, 2015), two different panel-data specifications, a dynamic panel two stage least squares model and Arrellano and Bond's (1991) generalized method of moments (GMM) estimator of a dynamic panel-data model, are employed in this study. The dynamic GMM estimator employs instrumental variables (IV) that address the problem of endogeneity among the explanatory variables and avoids estimation bias that is associated with the correlation between the lagged dependent variable and the error term (Omri et al., 2014). According to Wooldridge (2001), the panel two-stage model is the most efficient IV estimator.

The remaining study is structured as follows. In Section 2, we review the related literature. In Section 3, we describe data. In Section 4, we outline the methodology. In Section 5, we analyse the estimation results. Finally, in Section 6 we offer some concluding remarks.

\section{Literature Review}

Natural gas was produced from coal when it was first used in commercial quantities in Britain in 1785 (Soldo, 2012). Soon after, natural gas was obtained by drilling and attracted less attention since associated gas was mostly flared. However in recent times, studies on the demand for natural gas have been proliferating due to climate change concerns, the safety of nuclear energy, increased discovery of gas and associated gas, environmental concerns about natural gas flaring and the need for an affordable source of fuel. In addition, the need to find a suitable complement or substitute for crude oil has also shifted attention to natural gas. Natural gas consumption has been studied extensively, especially within the last 30 years, due to its growing environmental and economic impacts among other consumption goods, with a particular emphasis on price elasticities (Bilgili, 2014). In particular, regional studies on price elasticity include 18 OECD countries (Griffin, 1979) ${ }^{1}$, West Germany and France

\footnotetext{
${ }^{1}$ For instance, Griffin (1979) investigates natural gas demand functions for different sectors of 18 OECD countries including Austria, Belgium, Canada, Denmark, France, West Germany, Greece, Ireland, Italy, Japan, Netherlands, Norway, Spain, Sweden, Switzerland, Turkey, United Kingdom and the USA over the period 1955 to 1974 . He finds that the price elasticity of natural gas varied between -0.83 to -1.60 .
} 
(Estrada and Fugleberg, 1989) ${ }^{2}$, Kuwait (Eltony, 1996) ${ }^{3}$, 12 European countries (Nilsen et al., $2005)^{4}$, and a broader sample of European and OECD countries (Dilaver et al., 2014) ${ }^{5}$, and Bangladesh (Wadud et al., 2011) ${ }^{6}$. Table 1 illustrates key characteristics of the existing body of research.

A growing body of literature investigates the relation between natural gas consumption and economic growth, with a particular emphasis on Bangladesh (Das et al., 2013) ${ }^{7}$, Pakistan (Shabbaz et al., 2013) ${ }^{8}$, and a panel of eight OECD countries (Bigli, 2014) ${ }^{9}$. By contrast studies on natural gas demand in Africa are virtually non-existent. The total production of natural gas in sub-Saharan Africa in 2011 was estimated to be 1,690 billion cubic feet (Bcf). Nigeria contributed $(66 \%)$ of the total gas produced, Equatorial Guinea (14\%), Mozambique (8\%), Ivory Coast (3\%) and South Africa (3\%) (EIA, 2013). In contrast, the two largest natural gas producers in the world, the USA and Russia, produced 22,902 Bcf and 21,436 Bcf respectively, and the world total production was 116,230 $\mathrm{Bcf}(\mathrm{BP}, 2013)$.

\footnotetext{
${ }^{2}$ Estrada and Fugleberg (1989) study the price responsiveness of natural gas demand for West Germany and France and found estimated price elasticities varying between -0.75 and -0.82 for West Germany and from -0.61 to -0.76 for France.

${ }^{3}$ Eltony (1996) models the demand for natural gas in Kuwait and finds that natural gas demand is inelastic to price and income in both the short and long run.

${ }^{4}$ Nilsen et al. (2005) examine natural gas demand per capita in 12 European countries including Austria, Belgium, Denmark, Finland, France, Germany, Ireland, Italy, Netherlands, Spain, Switzerland and UK over the period 1978-2002. Their results suggest that the short run and long run price elasticities vary between 0 to -0.3 and 0 to -0.6 respectively, whereas the short and long run income elasticities range from 0.3 to 0.7 and 1.9 to 2.2 correspondingly.

${ }^{5}$ Dilaver et al. (2014) investigate the impact of income, real natural gas prices and the underlying energy demand trend (UEDT) on OECD-Europe natural gas consumption by applying the structural time series technique to annual data over the period 1978 to 2009. The results suggest that income, the UEDT and natural gas prices all play a major role in driving OECD-Europe natural gas consumption. The estimated long run income and price elasticities are 1.16 and -0.17 respectively.

${ }^{6}$ Wadud et al. (2011) use the partial adjustment model to natural gas demand in Bangladesh and find a long run income elasticity of 1.5 .

${ }^{7}$ Das et al. (2013) apply the Vector Error Correction Model (VECM) to natural gas demand in Bangladesh and find that there is a unidirectional relation from economic growth to natural gas consumption.

${ }^{8}$ Shabbaz et al. (2013) examine the relationship between natural gas consumption and economic growth in a multivariate framework that includes capital, labour, and exports. The ARDL bounds testing approach and the findings indicate that natural gas consumption leads to growth in Pakistan.

${ }^{9}$ Bigli (2014) applies the panel data for eight Organization for Economic Cooperation and Development (OECD) countries to seek responses of per capita natural gas consumption to per capita income and natural gas price from 1979 to 2006 .
} 


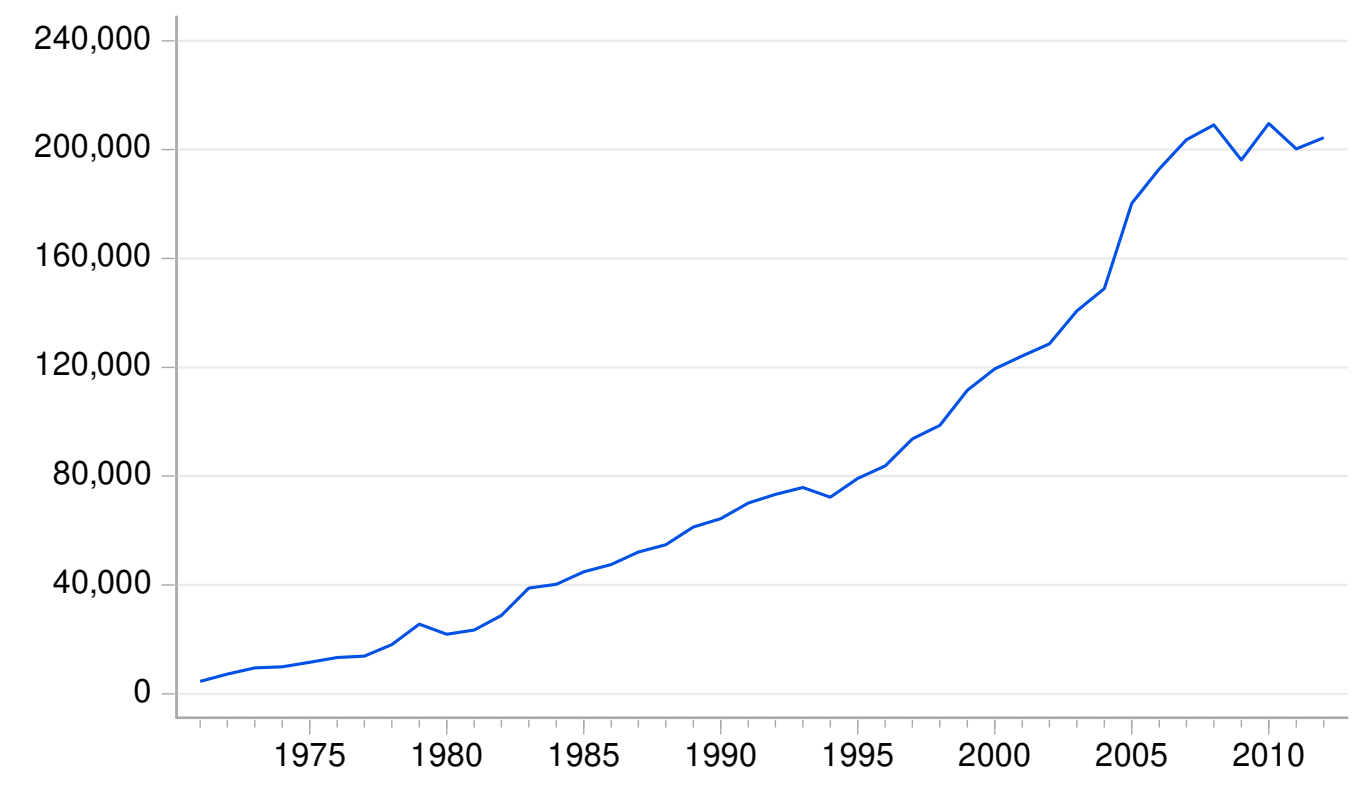

FIGURE 1. NATURAL GAS PRODUCTION IN BILLION CUBIC METERS IN AFRICA FROM 1971 TO 2012

Figure 1 shows Africa produced 4.5 billion cubic metres of natural gas in 1971. This increased to 204 billion cubic tonnes in 2012. The major natural gas suppliers in Africa over this period are Algeria, Angola, Cameroon, Congo, Cote d'Ivoire, Egypt, Equatorial Guinea, Gabon, Libya, Mozambique, Morocco, Nigeria, South Africa, and Tunisia. On the supply side, new natural gas field discoveries such as in Mozambique, technological improvements like hydraulic fracturing, LNG technologies, and new uses of gas in Africa such as for power generation and construction of pipelines to aid transportation have increased production. The demand emanates from (i) the industrial sector that uses natural gas for power generation and (ii) households that use natural gas for cooking and heating. The growing use of natural gas can be seen as a perfect substitute for charcoal. Household income and natural gas subsidies are thought to be the major drivers of demand for natural gas.

It is estimated that gas consumption in Africa has been growing at $6 \%$ per annum since 2000 and reached $210 \mathrm{bcm}$ in 2011 (BP, 2012). In terms of consumption, Egypt and Algeria account for more than $70 \%$ of total gas consumption in Africa for 2011 (IEA, 2013).

Ackah (2014) investigates the effect of economic (price, income, household final expenditure, industrial output) and non-economic factors (the underlying energy demand trend) on natural gas demand in Ghana at the aggregate and disaggregated levels. To capture the effects of the exogenous non-economic factors, a structural time series model is 
employed. The findings suggest that both economic and non-economic factors influence natural gas demand. It further reveals that different sectors respond differently to these factors. The study recommends that policies such as natural gas price subsidies should be customized for different sectors to obtain policy objectives.

Over the past 20 years, different econometric techniques such as the modified logit model (Mackay and Probert, 1995), the dynamic log-linear model (Nilsen et al., 2005), the bottom up approach (Honore, 2006), the autoregressive distributed lag model (Bernstein and Madlener, 2011), and the structural time series model (Dilaver et al., 2014) have been applied to energy demand studies.

TABLE 1. SUMMARY OF NATURAL GAS STUDIES

\begin{tabular}{|c|c|c|c|c|}
\hline Author & Method & Country & Period & Findings \\
\hline Liu (1983) & OLS & USA & 1960-1978 & $\begin{array}{l}\text { Price }=-0.49, \\
\text { Income }=0.55\end{array}$ \\
\hline $\begin{array}{l}\text { Estrada and } \\
\text { Fugleberg } \\
\text { (1989) }\end{array}$ & $\begin{array}{l}\text { Translog } \\
\text { functions }\end{array}$ & $\begin{array}{l}\text { West Germany } \\
\text { and France }\end{array}$ & & $\begin{array}{l}\text { Price }=-0.75 \text { to } \\
-0.82 \text { (West } \\
\text { Germany), } \\
-0.61 \text { to }-0.76 \\
\text { (France) }\end{array}$ \\
\hline Eltony (1996) & PAM, ECM & Kuwait & 1975-1993 & $\begin{array}{l}\text { Price }=-0.34 \\
\text { Income }=0.82\end{array}$ \\
\hline $\begin{array}{l}\text { Sunak and } \\
\text { Madlener } \\
\text { (2011) }\end{array}$ & ARDL & OECD-Europe & 1980-2008 & Price $=-0.51$ \\
\hline $\begin{array}{l}\text { Wadud et al. } \\
\text { (2011) }\end{array}$ & $\begin{array}{l}\text { Log-linear } \\
\text { Cobb Douglas } \\
\text { model }\end{array}$ & Bangladesh & 1981-2008 & $\begin{array}{l}\text { Price --- } \\
\text { Income }=1.5\end{array}$ \\
\hline Ackah (2014) & $\begin{array}{l}\text { Structural time } \\
\text { series model }\end{array}$ & Ghana & 1989-2009 & $\begin{array}{l}\text { Price }=-1.81 \\
\text { Income }=1.95\end{array}$ \\
\hline $\begin{array}{l}\text { Dilaver et al. } \\
\text { (2014) }\end{array}$ & $\begin{array}{l}\text { Structural time } \\
\text { series model }\end{array}$ & OECD-Europe & $1978-2011$ & $\begin{array}{l}\text { Price }=-0.16 \\
\text { Income }=1.19\end{array}$ \\
\hline
\end{tabular}

Three categories of determinants of natural gas demand can be identified. The first category of determinants comprises economic factors such as the price of the type of energy, the prices of substitutes and complements, and income. The second category comprises demographic and consumer characteristics such as population, the frequency and intensity of use, and consumer choice of energy using appliances. The third category accommodates environmental and technological factors such as average weather conditions, the efficiency of 
the energy using appliances, productivity of the appliances, environmental laws and regulations.

\section{Data}

The study seeks to identify the determinants of natural gas demand in oil producing African countries. To this end, we build upon Balestra and Nerlove (1966), Estrada and Fugleberg (1989) and Erdogdu (2010), who estimate the effect of price and income on natural gas demand. More specifically, we use a panel-data model that combines a time dimension and a cross section of countries. The time dimension consists of annual data and spans from 1971 to 2012.

The use of income as a key explanatory variable is motivated by Cleveland et al. (2000) and Ayres et al. (2007). The role of price as a driver of demand for natural gas has received considerable attention (Gately and Huntington, 2002, Wadud et al., 2010). The specific countries selected and the timeframe are dictated by data availability. These countries are Algeria, Angola, Egypt, Nigeria and Tunisia which together consume more than $90 \%$ of natural gas in Africa (EIA, 2013). These five countries have been selected because they constitute the major consumers of Natural Gas among oil producing countries in Africa.

Natural gas is principally used for power generation, for fertilizer manufacturing, as a transport fuel, and in households for cooking. The IEA (2011) forecasts that the share of natural gas in global energy mix will rise from $21 \%$ in 2010 to $25 \%$ in 2035 . This rise is principally driven by increased use of natural gas in transportation, low growth in nuclear energy and discovery of conventional and unconventional (shale) gas. In Africa, a series of major natural gas infrastructure projects have been carried out that have led to higher demand for natural gas. Notable among them are the West African Gas Pipeline that stretches from Nigeria through Benin and Togo to Ghana and huge gas discoveries in Mozambique, Nigeria, Angola and Tanzania. In terms of natural gas reserves, the African Development Bank estimates that Algeria, Egypt, Libya and Nigeria possess about 91\% of Africa's gas reserves. An Ernst and Young 2012 report describes natural gas as a 'prime mover' for broader economic development in Africa. According to the BP Statistical Review (2012), natural gas consumption in Africa has been growing at an annual rate of 6\% since 2010. BP (2012) estimates that Egypt and Algeria accounted for $70 \%$ of Africa's total gas consumption in 2011. 
Data on GDP in current US dollars, our proxy for income, are obtained from the World Bank development indicators. Obtaining data on natural gas prices from reliable sources in the various countries is a daunting task. Therefore, following Mahadevan and Asafu-Adjaye (2007), consumer price index (CPI) of the base year 2000 is used as a proxy for natural gas prices. The choice of CPI as a proxy for the energy price variable was informed by two reasons. First, there is unavailability of consistent data on energy prices on the countries under consideration. Second, studies, such as Mahadevan and Asafu-Adjaye (2007) and Tang et al. (2013) used CPI as a proxy for energy price when they carried out similar studies on Africa. Annual data on natural gas consumption in kilogramme of oil equivalent is obtained from the International Energy Agency. Table 2 shows the descriptive statistics of the data. Five countries are used in this study. These are Algeria, Angola, Egypt, Nigeria, and Tunisia.

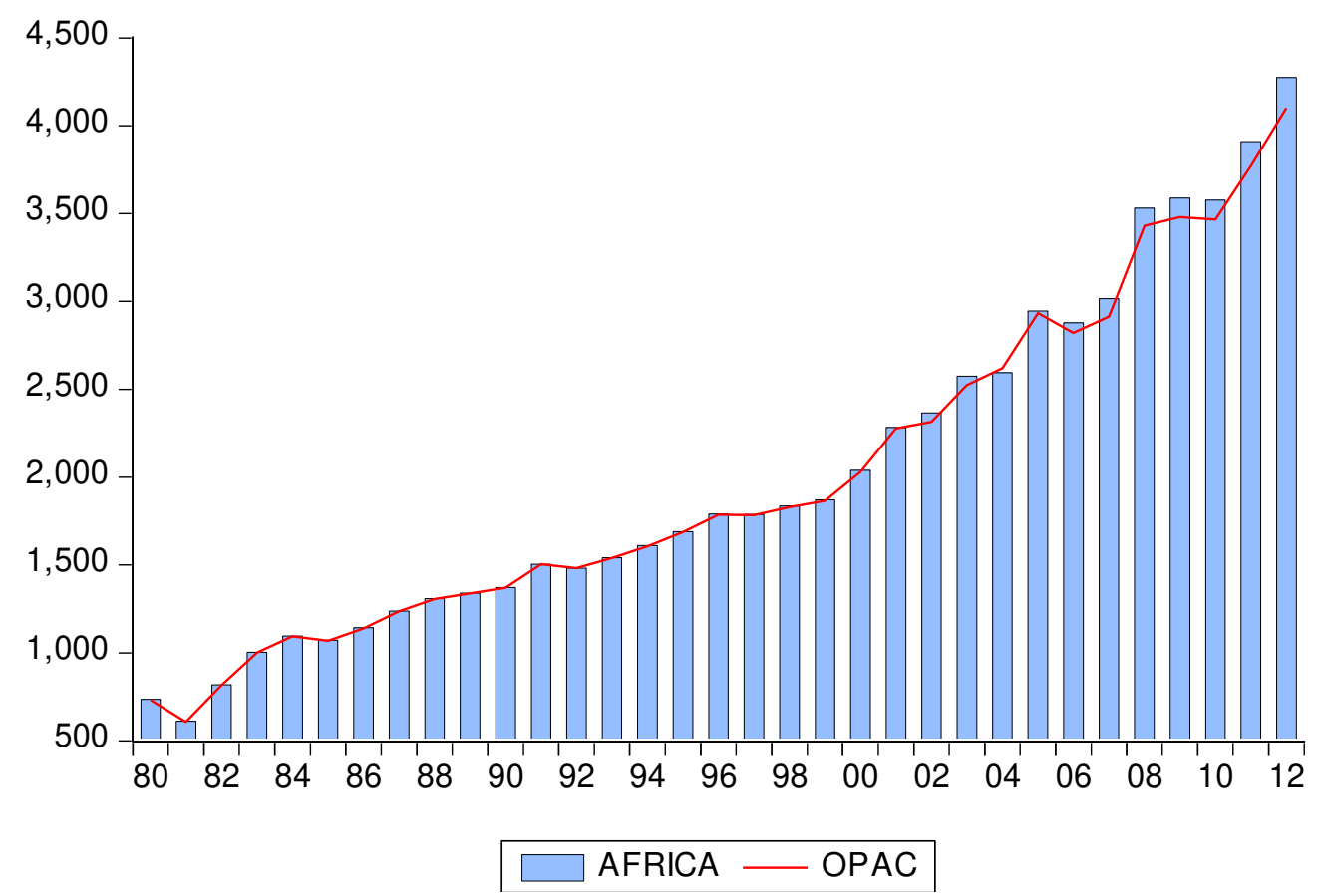

FIGURE 2. NATURAL GAS CONSUMPTION TREND 1980 - 2012

Figure 2 shows natural gas demand trend and energy related carbon emissions. Apart from Angola, the trend shows that as natural gas consumption increases energy related carbon emissions increase. Angola has been able to reduce carbon emissions through a UN sponsored REDD+ (Reducing Emissions from Deforestation and Forest Degradation) programme that helps to avoid deforestation, increased renewable energy consumption, 
distribution of compact fluorescent lamps (CFLs) and efficient stoves and reduction in natural gas flaring (Lutken et al., 2013).

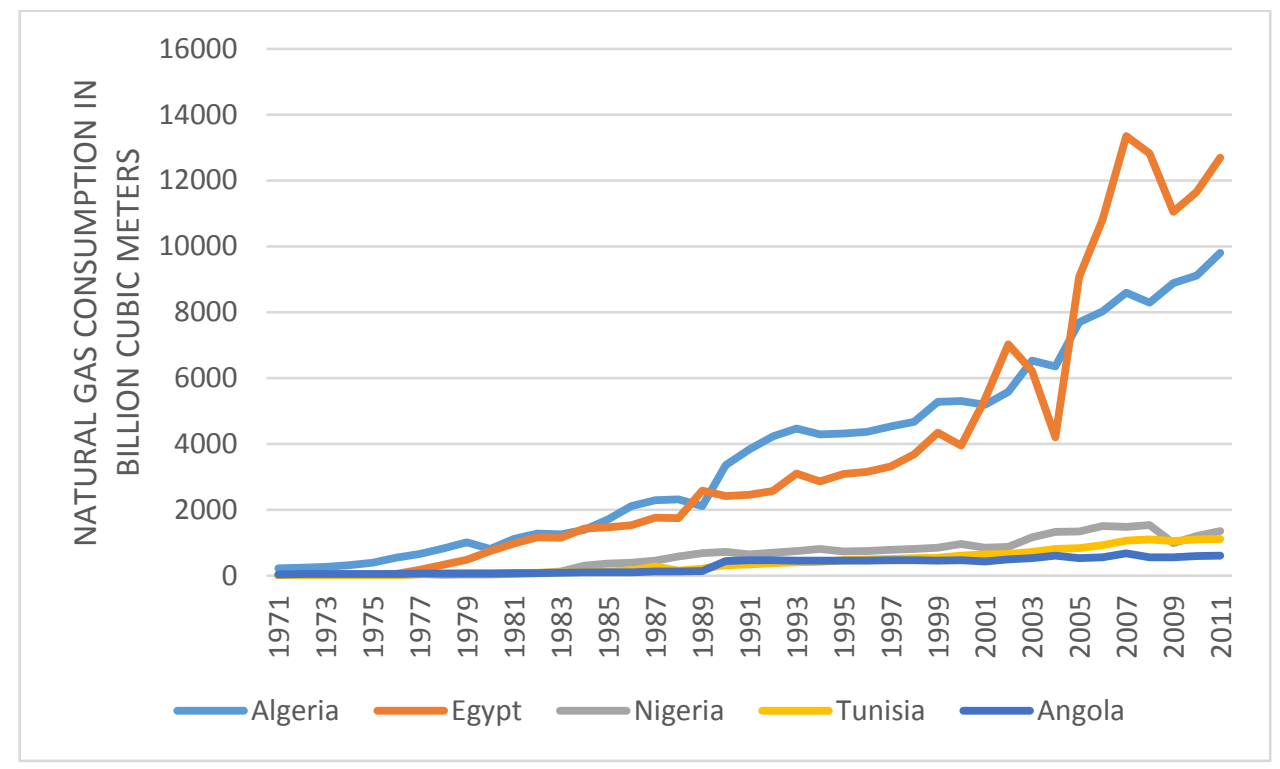

FIGURE 3: TREND IN NATURAL GAS CONSUMPTION IN THE 5 SELECTED OIL PRODUCING AFRICAN COUNTRIES

GDP in current US dollars serves as a proxy for cumulative economic growth. Consumer price index (CPI) proxies for accumulated changes in energy prices. Both GDP and CPI are obtained from the World Bank Development indicators. Our sample includes Algeria, Angola, Egypt, Nigeria and Tunisia.

TABLE 2. DESCRIPTIVE STATISTICS

\begin{tabular}{l|ccccc}
\hline \multicolumn{1}{c|}{ Statistic } & $\mathbf{G}$ & $\mathbf{P}$ & $\mathbf{Y}$ & $\mathbf{E D}$ & $\mathbf{C O}_{2}$ \\
\hline Mean & 2076.431 & 52.51237 & $5.26 \mathrm{E}+10$ & $8.39 \mathrm{E}+09$ & 15.60770 \\
Median & 807.5000 & 41.16544 & $3.59 \mathrm{E}+10$ & $4.66 \mathrm{E}+09$ & 9.690000 \\
Maximum & 13351.00 & 211.3093 & $4.14 \mathrm{E}+11$ & $4.98 \mathrm{E}+10$ & 86.73000 \\
Minimum & 0.000000 & $4.14 \mathrm{E}-08$ & $4.06 \mathrm{E}+09$ & 82648876 & 0.280000 \\
Std. Dev. & 2889.033 & 50.63241 & $5.86 \mathrm{E}+10$ & $1.05 \mathrm{E}+10$ & 17.24766 \\
Skewness & 2.091713 & 0.769637 & 3.035148 & 2.019803 & 1.965628 \\
Kurtosis & 6.879640 & 2.797838 & 15.44202 & 6.620334 & 7.009050 \\
Jarque-Bera & 236.0068 & 17.47421 & 1389.479 & 213.3329 & 228.5727 \\
Prob & 0.000000 & 0.000161 & 0.000000 & 0.000000 & 0.000000 \\
\hline
\end{tabular}

Notes: This table summarizes descriptive statistics (sample mean, median, maximum, minimum, standard deviation, skewness, kurtosis, the Jarque-Bera test statistic, and the p-value associated to the Jarque-Bera test statistic) of natural gas consumption $(\mathrm{G}$, in $\mathrm{kg}$ of oil equivalent per capita), the price level ( $\mathrm{P}$, consumer price 
index), gross domestic product (Y, in real 2005 US dollars per capita), ED for natural resource depletion and CO2 emissions (in tonnes per capita) and. The sample period runs from 1971 to 2012 for five countries (Algeria, Angola, Egypt, Nigeria, and Tunisia).

Over the sample period and across countries, the mean of GDP is 52.6 billion of US Dollars according to Table 2 . The degree of variability is also witnessed by the standard deviation. The data for this variable are positively skewed and leptokurtic with the value of the skewness at 3.04 and the value of kurtosis at 15.44. The positive value of the kurtosis suggests that the positive deviation across the countries is more dispersed than the negative deviations. The latter suggests that the distribution of real GDP across countries and over time features heavy tails, whereas the former suggests that positive deviations from the mean tend to be more dispersed than negative deviations.

Energy depletion averages 8.39 billion of current US Dollars across countries and over time. Energy depletion varies over time ranging from USD 0.083 billion to USD 49.8 billion. The data are positively skewed with a skewness value of 2.02 and a kurtosis value of 6.62 which result in the rejection of the null of non-normality. $\mathrm{CO} 2$ emissions have an estimated mean of 15.61 metric tonnes per capita. Again, we observe negative skewness. The price level averages 52.51 across countries and over time. Finally, natural gas demand averages 2.076 million cubic metres. The positive value of skewness (2.09) and kurtosis (6.880) provide evidence of non-normality in the data.

\section{TABLE 3. COEFFICIENTS OF CORRELATION}

\begin{tabular}{c|ccccc}
\hline & G & Y & ED & P & CO2 \\
\hline $\mathbf{G}$ & 1.00 & & & & \\
$\mathbf{Y}$ & 0.61 & 1.00 & & & \\
$\mathbf{E D}$ & 0.44 & 0.77 & 1.00 & & \\
$\mathbf{P}$ & 0.42 & 0.52 & 0.19 & 1.00 & 1.00 \\
$\mathbf{C O}$ & 0.69 & 0.73 & 0.39 & 0.61 & \\
\hline
\end{tabular}

Notes: This table summarizes the Pearson coefficients of natural gas consumption $(\mathrm{G})$, energy price $(\mathrm{P})$, gross domestic product $(\mathrm{Y})$, energy resource depletion (ED) and energy related carbon emissions (CO2) for Algeria, Angola, Egypt, Nigeria and Tunisia from 1971 to 2012.

Table 3 summarizes the Pearson coefficients among natural gas consumption, GDP, energy resource depletion, price and carbon emissions. The sample period runs from 1971 to 2012 for five countries (Algeria, Angola, Egypt, Nigeria and Tunisia). The result indicates that 
natural gas consumption is positively correlated with all the explanatory variables included in this study. With respect to correlation among the explanatory variables, the highest correlation was found between Gross Domestic Product and energy resource depletion (0.77) which is positive followed by a positive correlation between GDP and $\mathrm{CO}_{2}$ emissions (0.73). Energy price was also found to be positively correlated with $\mathrm{CO}_{2}$ emissions (0.61) as well as positively correlated with GDP (0.52). Also, energy resource depletion was found to have a weak positive correlation with energy price (0.19) and $\mathrm{CO}_{2}$ emissions (0.39). It must however be cautioned that correlation only indicates the direction and magnitude of relationship among the variables but does not imply causality.

\section{The Model}

The demand for natural gas depends on many factors such as price of natural gas, income and environmental factors (Wadud et al., 2011). Functional forms like linear, log-linear and translog can be used to mathematically express the relations between natural gas demand and the predictors. According to Kaboudan and Liu (2004), log-linear models represent the nonlinear nature of the variables better. In addition, the log-linear functions directly provide the elasticities of demand with respect to the predictors.

According to Bruno (2005) the usual panel fixed and random models are inconsistent when the time span of the study is small. In such cases, Anderson and Hsiao (1982) recommend that instrumental variables, or the Arrellano Bond estimator through the generalized method of moments is preferred. This study seeks to investigate the predictors of natural gas demand in oil producing African countries. Natural gas demand is modelled as a function of an array of explanatory variables and a random disturbance:

$G_{i, t}=F\left(P_{i, t}, Y_{i, t}, E D_{i, t}, C O 2_{i, t}, u_{i, t}\right)$

where $i=1, \ldots, N$ sub-indexes coun,tries and $t=1, \ldots, T$ index time periods. Equation (1) relates natural demand $\left(G_{i, t}\right)$, energy price $\left(P_{i, t}\right)$, gross domestic product $\left(Y_{i, t}\right)$, energy depletion $\left(E D_{i, t}\right)$, energy-related carbon emissions $\left(C O 2_{i, t}\right)$ and the stochastic disturbance $\left(u_{i, t}\right)$. Energy consumption and GDP are shown to be positively related in the energy economics literature (see also Cleveland, 2000, Ayres et al., 2007, among others). In addition, the inverse relation between price and energy demand has received considerable attention in the literature (Gately and Huntington, 2002, Graham and Glaister, 2002, Wadud et al., 2011). 
According to Ibrahim and Hurst (1990), due to lack of information, energy demand studies in developing countries often use only price and income as predictors. In this study, we additionally consider energy related carbon emissions (CO2) and energy resource depletion are added as predictors. Indeed, all fossil fuels including natural gas emit CO2 (Marland, 2008). Further, since natural gas is non-renewable, it is presumed that energy resource depletion can influence gas consumption. We assume that the relation between natural gas demand and its potential determinants takes on a parsimonious linear form as follows:

$G_{i, t}=\beta_{0}+\beta_{G} G_{i, t-1}+\beta_{Y} Y_{i, t}+\beta_{P} P_{i, t}+\beta_{E D} E D_{i, t}+\beta_{C O 2} C O 2_{i, t}+u_{i, t}$

According to Suganthi and Samuel (2012), the use of panel methods in energy demand is limited. In this study, the dynamic panel GMM and the dynamic panel TSLS with instrumental variables are employed to estimate the determinants of natural gas demand. Omri (2014) posits that the inclusion of instrumental variables helps to overcome the endogeneity problem. Following the study of Omri (2014) this study employed the lag values of the dependent and independent variables were used as instruments. It also avoids estimation bias that is associated with the correlation between the lagged dependent variable. Equation (2) is estimated with panel GMM and panel TSLS.

However, we recognize that energy does not produce output by itself but works through capital stocks and other mediums to produce a given output, the efficiency of the capital stock influences the amount of energy use in the production process. In addition to the efficiency of the capital stock, price and income change, 'taste' has also been found to influence energy consumption. According to Hunt et al., (2003), the addition of technological progress, efficiency of the capital stock and 'taste' is referred to as the Underlying Energy Demand Trend (UEDT). This study applies an automatic variable selection procedure to identify the predictors of natural gas demand for each country and ascertain the underlying energy demand trend.

Hendry and Krolzig (2005) suggest that model selection is a vital step in empirical research especially where (i) a prior does not predefine a complete and correct generally accepted specification and (ii) there is room for exploratory modelling. Since a large set of factors can potentially influence the demand for natural gas, it is prudent to have an econometric procedure that automatically selects the significant factors based on some predefined criteria. For Africa, Bhattacharya and Timilsina (2009) suggest that due to factors such as the 
transition from traditional sources of energy to modern commercial ones and the economic structure, the energy demand functional form may depart from the ones that specify energy demand as a function of energy price and income. The automatic variable selection proceeds in a general-to-specific fashion. It works by first specifying a general model based on previous findings, geographic and demographic characteristics, technological and economic trends. Misspecification tests, lag structures, significance levels and the desired information criteria are then set. Such procedure allows valid inference from the selected specification (Hendry and Krolzig, 2005). All insignificant variables are eliminated.

In order to examine the determinants of natural gas demand for specific countries, a general unrestricted model (GUM) consisting of all predictors is specified. Autometrics then uses a tree-search to remove insignificant variables to select the final model (Pellini, 2014). We begin by specifying a GUM error correction model featuring impulse indicator and step dummies.

$\beta_{G}(L) G_{i, t}=\beta_{0}+\beta_{1} t+\beta_{P}(L) P_{i, t}+\beta_{Y}(L) Y_{i, t}+\beta_{E D}(L) E D_{i, t}+\beta_{C O 2}(L) C O 2_{i, t}+\sum_{j=1}^{J}\left(\beta_{j} I_{j, t}+\delta_{j} S_{j, t}\right)+u_{i, t}$

Where $i$ indexes country, $t$ indexes time, $I_{j, t}$ is the impulse indicator dummy and $S_{j, t}$ is a step dummy. For all dummies, $j$ is the indicator index. For instance, $I_{2004, t}$ means the impulse indicator dummy variable for 2004 that takes on the value 1 for 2004 and 0 prior to 2004 . $\beta(L)$ denotes a lag polynomial. In order to enhance the robustness of the model, a battery of misspecification tests are used to evaluate it. These tests include the autocorrelation test (Breusch and Godfrey, 1981) where the null hypothesis stipulates no serial correlation in the residuals. Moreover, the ARCH test (Engle, 1982) where the null stipulates no serial correlation in the squared residuals is employed. Other tests include the normality test (Bera and Jarque, 1982) which tests the normality assumption in residuals, the heteroskedasticity test (Breusch and Pagan, 1979) that tests the assumption of constant error variance, and finally, the Reset test (Ramsey, 1974) which tests for linearity in the functional form of the regression.

\section{Results and Discussions}

We estimate three models to ascertain the determinants of natural gas demand in oil producing African countries. These are the dynamic panel generalized method of moments, 
the two stage least squares and general unrestricted model. Table 4 presents the results of the dynamic GMM. According to Fang et al. (2011), the use of instrumental variables in GMM addresses the endogeneity problem. In specifications (1) to (5), the predictors of natural gas demand enter the regression individually whilst specification (6) employs the full set of predictors.

\subsection{Results from the Dynamic Panel GMM}

TABLE 4. ESTIMATION RESULTS - DYNAMIC PANEL GMM

\begin{tabular}{l|llllll}
\hline Predictor & $(1)$ & $(2)$ & $(3)$ & $(4)$ & $(5)$ & $(6)$ \\
\hline G (-1) & $\mathbf{0 . 9 1 7}$ & & & & & $\mathbf{0 . 9 9 9}$ \\
& $(0.014)$ & & & & $(0.030)$ \\
P & & $\mathbf{- 0 . 0 3 2}$ & & & & $\mathbf{- 0 . 0 3 3}$ \\
& & $(0.011)$ & & & & $(0.017)$ \\
Y & & $\mathbf{0 . 0 3 2}$ & & & $\mathbf{0 . 0 2 8}$ \\
& & & $(0.094)$ & & & $(0.013)$ \\
ED & & & & $-\mathbf{0 . 4 4 1}$ & & 0.025 \\
& & & & $(0.0095)$ & & $(0.017)$ \\
CO2 & & & & & 0.167 & 0.026 \\
& & & & & $(0.130)$ & $(0.024)$ \\
\hline R2 & & 0.961 & 0.957 & 0.948 & 0.941 & 0.966 \\
DW & & 0.505 & 0.42 & 0.385 & 0.302 & 1.94 \\
\hline N & & & & & & \\
\hline
\end{tabular}

Note: Standard errors are reported in parentheses. The coefficient estimates highlighted in bold are significant at the significance level of $5 \%$.

Table 4 reports the results from the panel dynamic GMM estimation. In tandem with general findings in the energy economics literature (Balestra and Nerlove 1966, Erdogdu 2010, Andersen et al., 2011), GDP has a positive and significant effect on natural gas demand. When income increases, consumers buy natural gas using appliances or increase the frequency of use of existing appliances such as natural gas cylinders leading to increased gas consumption. In addition, increased income leads to increased demand for electricity. Since natural gas is an input into electricity generation, gas consumption increases through additional power generation (Hultman et al., 2011). In both the individual and group specifications, GDP is positive and significant. Specification (3) reports that $1 \%$ increase in GDP leads to an increase of $0.032 \%$ in natural gas consumption. This is supported by the findings of specification (6) which reports that $1 \%$ increase in GDP leads to $0.028 \%$ increase 
in natural gas consumption. The positive and significant relations between natural gas demand and GDP underscores the importance of energy policies that encourage the accessibility and availability of energy demand. Investments in cross-border natural gas infrastructure such as the West African Gas Pipeline that stretches from Nigeria to Ghana, should be taken to enhance regional economic growth. The positive relationship between income and energy demand has been widely documented (Cleveland et al., 2000 and Ayres et al., 2007). In addition, the inverse relationship between price and energy consumption has received considerable attention (Gately and Huntington, 2002, Wadud et al., 2010). It has been suggested however that there are other factors such as technological progress, lifestyle and economic structure that affect the demand for natural gas or energy apart from price and income (Bhattacharya and Timilsina, 2009).

The estimated price effect is significant in both specifications (2) and (6). The results show that price has an inverse relationship with natural gas demand. These results vindicate Mahadevan and Asafu-Adjaye (2007) who identify a negative and significant price effect on energy demand. According to Table 4, $1 \%$ increase in price reduces natural gas demand by $0.032 \%$ in specification (2) and $0.033 \%$ in specification (6).

Moreover, natural gas is a non-renewable source of energy. This means as a unit of gas is drawn, the remaining amount reduces. In order to test whether this concept has an impact on demand, a variable for energy resource depletion was introduced into the model. This is to measure whether energy resource depletion has any effect on natural gas demand. Though the effect of natural resource depletion in specification (6) is insignificant at 5\%, results from specification (4) $1 \%$ increase in energy resource depletion reduces natural gas consumption by $0.441 \%$. This may imply that other energy sources such as renewable energy are used as alternatives for power generation and cooking.

Since non-renewable sources of energy such as coal, oil and natural gas emit carbon dioxide, the study also examines how carbon emissions affect the consumption of natural gas. Table 4 reports that though the estimates for carbon dioxide in specifications (5) and (6) are positive, they are not significant.

\subsection{Results from the Dynamic Panel Two Stage Least Square (DP-TSLS)}

TABLE 5. ESTIMATION RESULTS - DYNAMIC PANEL TWO STAGE LEAST SQUARES 


\begin{tabular}{|c|c|c|c|c|c|c|}
\hline Predictor & (1) & (2) & (3) & (4) & (5) & (6) \\
\hline G (-1) & $\begin{array}{c}\mathbf{0 . 6 8 7} \\
(0.046)\end{array}$ & & & & & $\begin{array}{c}\mathbf{0 . 9 5 2} \\
(0.018)\end{array}$ \\
\hline $\mathbf{P}$ & & $\begin{array}{l}\mathbf{- 0 . 0 3 5} \\
(0.013)\end{array}$ & & & & $\begin{array}{l}\mathbf{- 0 . 0 2 8} \\
(0.010)\end{array}$ \\
\hline $\mathbf{Y}$ & & & $\begin{array}{c}\mathbf{1 . 1 5 4} \\
(0.094)\end{array}$ & & & $\begin{array}{r}\mathbf{0 . 0 6 2} \\
(0.027)\end{array}$ \\
\hline ED & & & & $\begin{array}{l}\mathbf{- 0 . 4 1 8} \\
(0.092)\end{array}$ & & $\begin{array}{l}-0.052 \\
(0.032)\end{array}$ \\
\hline $\mathrm{CO} 2$ & & & & & $\begin{array}{c}\mathbf{0 . 0 0 4} \\
(0.002)\end{array}$ & $\begin{array}{c}\mathbf{0 . 0 6 4} \\
(0.021)\end{array}$ \\
\hline $\mathbf{R} 2$ & 0.987 & 0.959 & 0.957 & 0.954 & 0.948 & 0.969 \\
\hline DW & 1.680 & 0.461 & 0.420 & 0.431 & 0.345 & 1.990 \\
\hline
\end{tabular}

Table 5 presents the results of the dynamic panel two stage least square (DP-2SLS) model for natural gas demand in oil producing African countries. The findings are qualitatively similar to those of the dynamic panel GMM. Consistently, in the GMM estimation of the model, the lagged dependent value of natural gas consumption is positive and significant. This implies that the previous year's consumption follows a long memory process. According to Table 5, an increase in previous year's consumption of $1 \%$ leads to an increase in current consumption of $0.687 \%$ (1) and $0.952 \%$ (6). This increase may be as a result of improved standard of living, population higher birth rate or increased demand for electricity.

\subsection{Results from the General Unrestricted Model}

This section discusses the results of the general unrestricted model.

TABLE 6. ESTIMATION FROM THE GUM MODEL

\begin{tabular}{l|ccccc}
\hline Predictors & Algeria & Angola & Egypt & Nigeria & Tunisia \\
\hline G(-1) & $\mathbf{0 . 4 6 4}$ & $\mathbf{0 . 3 0 3}$ & $\mathbf{0 . 3 5 3}$ & $\mathbf{0 . 7 2 9}$ & $\mathbf{0 . 7 0 0}$ \\
& $(0.135)$ & $(0.155)$ & $(0.084)$ & $(0.025)$ & -0.156 \\
$\mathrm{P}$ & $\mathbf{- 1 . 1 9 6}$ & & & & \\
& $(0.327)$ & & & & \\
$\mathrm{Y}$ & $\mathbf{0 . 1 3 4}$ & & $\mathbf{0 . 6 5 2}$ & $\mathbf{0 . 1 3 3}$ & $\mathbf{0 . 6 3 1}$ \\
& $(0.031)$ & & $(0.098)$ & $(0.022)$ & $(0.046)$ \\
$\mathrm{ED}$ & & & $\mathbf{0 . 1 0 6}$ & $\mathbf{- 0 . 2 5 4}$ & \\
& & & $(0.021)$ & $(0.020)$ &
\end{tabular}




\begin{tabular}{|c|c|c|c|c|c|}
\hline $\mathrm{CO} 2(-1)$ & \multicolumn{5}{|c|}{0.574} \\
\hline $\mathrm{CO} 2(-2)$ & & & $\begin{array}{c}\mathbf{0 . 2 0 1} \\
(0.068)\end{array}$ & & \\
\hline I(1984) & & & & & $\begin{array}{c}\mathbf{0 . 1 8 0} \\
(0.015)\end{array}$ \\
\hline$S(2003)$ & & & $\begin{array}{c}\mathbf{0 . 2 1 9} \\
(0.050)\end{array}$ & & \\
\hline$S(2004)$ & & $\begin{array}{c}-\mathbf{0 . 3 6 6} \\
(0.052)\end{array}$ & & & \\
\hline Diagnostics & & & & & \\
\hline AR 1-2 & 0.253 & 0.487 & 1.359 & 2.700 & 0.519 \\
\hline ARCH 1-1 & 0.033 & 0.048 & 2.905 & 1.521 & 0.004 \\
\hline Normality: & 5.914 & 0.653 & 2.137 & 0.999 & 1.364 \\
\hline Hetero test: & 0.598 & 1.053 & 1.342 & 1.058 & 0.664 \\
\hline Hetero- $\mathrm{X}$ test & 5.330 & 0.835 & 1.179 & & \\
\hline RESET23 & 1.908 & 0.816 & 1.025 & 0.119 & 1.757 \\
\hline $\mathrm{R} 2$ & 0.989 & 0.999 & 0.985 & 0.999 & 0.999 \\
\hline
\end{tabular}

Note: Standard errors are reported in parentheses. The coefficient estimates highlighted in bold are significant at the significance level of $5 \%$.

Table 6 shows the result of the model selected by the general to specific model selection procedure. Consistently with the conventional modelling strategy, five lags to each variable are used (see Hunt et al., 2003, Broadstock and Hunt, 2010). Autometrics selected step dummy (SI) variables for Nigeria in 1977, 1978, 1986, 1987, 1988, 1991, 2008 and 2009. The numerous step dummies for Nigeria may represent responses to changes in international oil price shocks in 1977/78, 1986 and 2008/2009. Price increases lead to energy efficiency measures and changes in lifestyle such as the energy efficiency standardization introduced in the early 1990's. The price variable is only significant for Algeria and Tunisia with Algeria recording the highest short and long run elasticities. The short run price elasticity for Algeria is -1.196 whilst the long run is -2.231. According to Wadud et al. (2011), for developing countries the elasticity estimates are often reported greater than unity. In terms of income, Egypt recorded the highest elasticity value in the short run. The model passed all (with few exceptions highlighted in bold) diagnostic tests and the estimates in Table 6 represent the preferred model. 


\subsection{Underlying Energy Demand Trend}

Energy has a derived demand. Therefore, the demand for all forms of energy, including natural gas, is a result of demand for energy services such as power generation, heating and cooling (Dilaver et al., 2014). This implies that the factors that influence the provision of these energy services play a vital role in determining the demand for natural gas. For instance, Dilaver et al. (2014) suggest that the capital stock and the efficiency of the capital through which energy services are provided is a key determinant of natural gas demand. However, Hunt et al. (2000) posit that the efficiency of the capital appliance is not the only exogenous factor that affects the demand for natural gas and cite energy regulations, consumer lifestyle, consumer values and changes in taste for appliances that could lead to a more or less energy intensive situation, and technological development as some of the other exogenous factors. It is therefore important to consider these exogenous factors when modelling the demand for natural gas (Hunt and Ninomiya, 2005, Doornat et al., 2008, Dilaver and Hunt, 2011). According to Hunt et al. (2000), the collective name for these exogenous factors is the underlying energy demand trend (UEDT).

In summary, the underlying energy demand trend shows the technical efficiency of energy using appliances. Hunt et al. (2003) explain that an upward slope implies that energy savings due to appliance efficiency have been consumed by excessive demand and inefficient behaviour. A downward trend of the UEDT implies energy saving behaviour which could be due to increased efficiency of the appliances used. This means consumers are using less energy to achieve the same results. Generally, the UEDT of the various countries imply that these countries have to do more to enhance energy efficiency and promote technological innovation in natural gas consumption. 


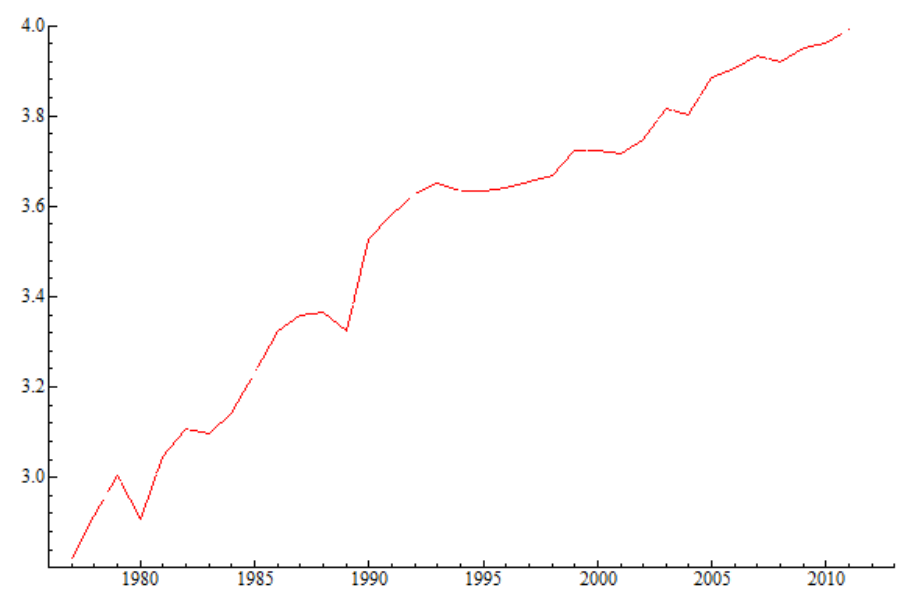

FIGURE 4. UEDT ALGERIA

The UEDT of Algeria shows an increasing trend with minor structural breaks in 1980 and 1990 (Figure 4). This trend implies that the excessive natural gas consumption offset the efficiency gains of technically efficient appliances over the estimation period. The UEDT is similar to the trend reported by Sa'ad (2011) for the aggregate energy demand in South Korea.

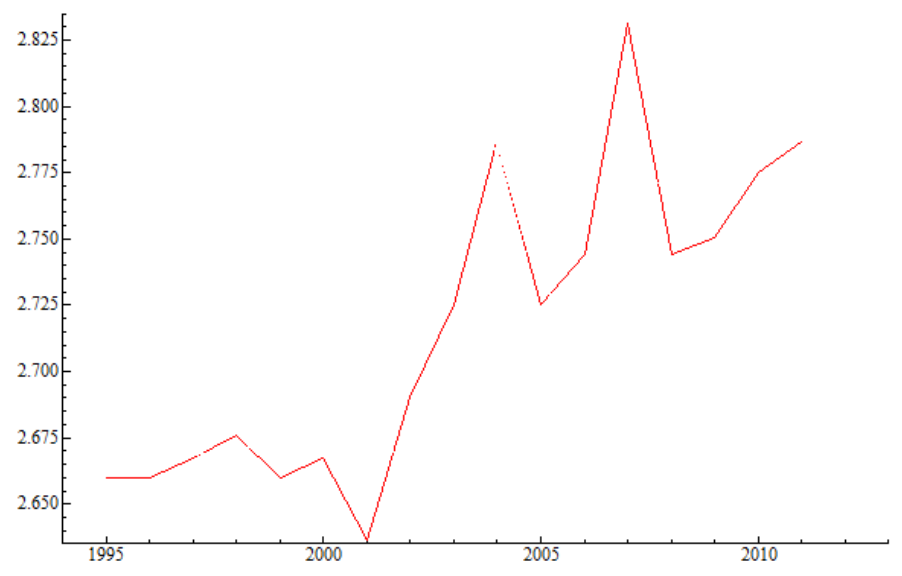

FIGURE 5. UEDT OF ANGOLA

Angola has initiated a number of energy efficiency measures over the last decade according to Lutken et al. (2013) (Figure 5). Although these measures are not reflected in the trend since it slopes upwards, there are major structural breaks in 2001, 2004, 2005, 2007 and 
2008. There was a downward trend from 2000 to 2001, 2004 to 2005 and 2007 to 2008. From 2009 , the trend has been increasing but relatively slower.

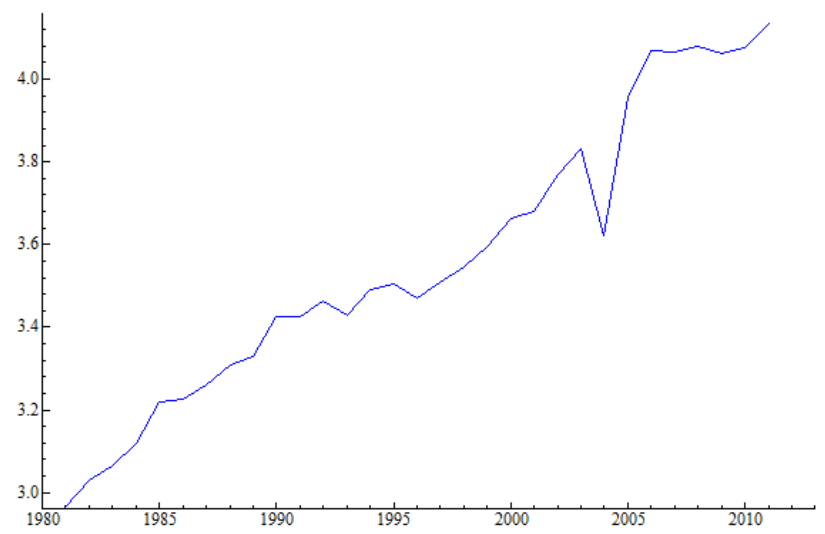

FIGURE 6. UEDT EGYPT

The underlying energy demand trend shows an upward slope with a structural break in 2004 (Figure 6). The trend implies that inefficiencies associated with natural gas consumption offset efficiency gains through the technical progress of appliances in Egypt.

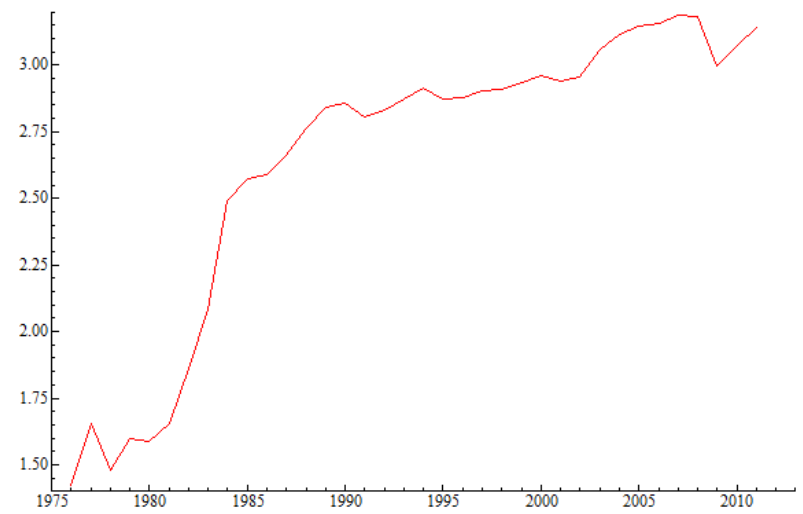




\section{FIGURE 7. UEDT NIGERIA}

According to Figure 7, Nigeria's UEDT has been relatively stable and the trend appears to flatten after 1991. This may be as a result of measures such as appliance standardization, efficiency education and other efficiency measures introduced after an energy efficiency study commissioned by the Nigerian Energy Commission and conducted by the Sokoto Energy Research Centre (Sambo, 2005).

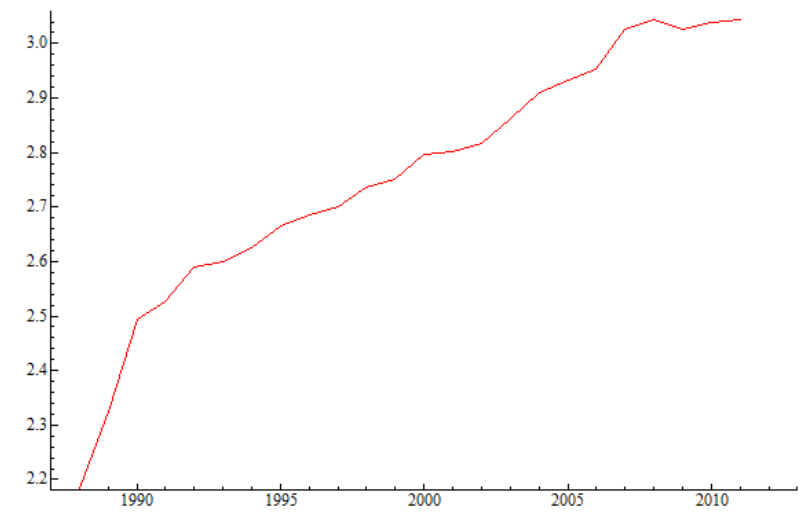

FIGURE 8. UEDT TUNISIA

The UEDT for Tunisia is similar to the trend reported by Pellini (2014) for France (Figure 8). The trend rises gradually with no major structural breaks signifying 'natural gas using' behaviour. This shows the inefficient consumption of natural gas indicating that over the years, households in Tunisia have exhibited an increasing demand of lighting, cooling and heating services that has more than offset the impact of improved technical efficiency of appliances.

\section{Conclusion and Recommendations}

Natural gas is considered a bridge fuel between renewable and non-renewable sources of energy. Apart from this, natural gas is relatively cheaper than oil, cleaner than oil and coal and widely available in oil producing African countries. This makes natural gas very attractive for domestic consumption, industrial usage and power generation in oil producing African countries. In this study, the predictors of natural gas demand in oil producing African countries are examined. In order to ensure the robustness of the findings, three models are used in this study. First, a dynamic panel generalized method of moments with instrumental variables that is capable of controlling for endogeneity is used. In addition, following the 
recommendation of Wooldridge (2011) who asserts that the dynamic panel two stage least squares is more efficient with IV, the study employs the panel TSLS as a second model to estimate natural gas demand. Finally, the structural time series model that is capable of modelling the underlying energy demand trend is applied. Five main variables including the lag dependent variable are used in this estimation. They are energy resource depletion, GDP, price and energy related $\mathrm{CO}_{2}$.

The results are in line with findings in existing literature. The study confirms the importance of all the predictors such as income, price, energy resource depletion and the lagged dependent variable on natural gas consumption in oil producing African countries. This notwithstanding, the model reported conflicting results for energy related $\mathrm{CO}_{2}$ and energy resource depletion. Moreover, the study finds that the countries under study have not been efficient in terms of natural gas consumption over the estimated period.

Based on the findings, the following recommendations are made. First, the advantages of natural gas consumption such as lower carbon emissions should be highlighted to encourage its consumption. In addition, effort should be made to encourage domestic natural gas consumption through gas availability by discouraging charcoal consumption. Again, effort should be made to encourage efficiency and technological innovation in natural gas consumption.

Whilst this paper made attempts to include all oil producing African countries, unavailability of data made it very challenging. Future research should explore other available datasets to include more countries. Finally, there should be conscious effort to encourage energy efficiency and demand side management to curb emissions and enhance energy conservation.

\section{References}

Ackah, I. (2014). Determinants of natural gas demand in Ghana. OPEC Energy Review, 38(3), 272-295.

Andersen, T. B., Nilsen, O. B., \& Tveteras, R. (2011). How is demand for natural gas determined across European industrial sectors? Energy Policy, 39(9), 5499-5508.

Anderson, T. W., \& Hsiao, C. (1982). Formulation and estimation of dynamic models using panel data. Journal of econometrics, 18(1), 47-82.

Apergis, N., \& Payne, J. E. (2010). Renewable energy consumption and economic growth: evidence from a panel of OECD countries. Energy policy, 38(1), 656-660. 
Aras, H., \& Aras, N. (2004). Forecasting residential natural gas demand. Energy Sources, 26(5), 463-472.

Arellano, M., \& Bond, S. (1991). Some tests of specification for panel data: Monte Carlo evidence and an application to employment equations. The Review of Economic Studies, 58(2), 277-297.

Ayres, R.U., Turton, H., \& Casten, T. (2007). Energy efficiency, sustainability and economic growth. Energy, 32, 634-648

Balestra, P., \& Nerlove, M. (1966). Pooling cross section and time series data in the estimation of a dynamic model: The demand for natural gas. Econometrica: Journal of the Econometric Society, 34(3), 585-612.

Bera, A. K., \& Jarque, C. M. (1982). Model specification tests: A simultaneous approach. Journal of econometrics, 20(1), 59-82.

Bhattacharyya SC and Timilsina GR 2009. Energy Demand Models for Policy Formulation: A Comparative Study of Energy Demand Models. Policy Research Working Paper 4866, The World Bank.

Bianco, V., Scarpa, F., \& Tagliafico, L. A. (2014). Scenario analysis of nonresidential natural gas consumption in Italy. Applied Energy, 113, 392-403.

Bilgili, F. (2014). Long run elasticities of demand for Natural Gas: OECD Panel Data Evidence. Energy Sources, Part B: Economics, Planning, and Policy, 9(4), 334-341.

BP Statistical Review of World Energy, June 2010. www.bp.com/statisticalreview

BP Statistical Review of World Energy, June 2012.

www.bp.com/statisticalreview.

BP. Statistical Review of World Energy 2013. BP p.1.c, 2013.

Broadstock, D. C., \& Hunt, L. C. (2010). Quantifying the impact of exogenous non-economic factors on UK transport oil demand. Energy Policy, 38(3), 1559-1565.

Breusch, T. S., \& Godfrey, S. (1981). "A review of recent work on testing for autocorrelation in dynamic simultaneous models." In D. Currie, R. Nobay, and D. Peel, (eds.), Macroeconomic Analysis. Croon-Helm, London.

Breusch, T. S., \& Pagan, A. (1979). A simple test of heteroskedasticity and random coefficient variation. Econometrica, 47, 1287-1294.

Bruno, G. S. (2005). Approximating the bias of the LSDV estimator for dynamic unbalanced panel data models. Economics Letters, 87(3), 361-366.

Cleveland, C., Kaufmann, R. K., \& Stern, D. I. 2000. Aggregation and the role of energy in the economy. Ecological Economics, 32, 301-317. 
Dilaver, Ö, Dilaver, Z., \& Hunt, L. C. (2014). What drives natural gas consumption in Europe? Analysis and projections. Journal of Natural Gas Science and Engineering, 19, 125136.

EIA [U.S. Energy Information Administration]. 2013. http://www.eia.gov. Oil and Natural Gas in Sub-Saharan Africa. 2013

Engle, R. (1982). "Autoregressive conditional heteroskedasticity with estimates of the variance of United Kingdom inflation." Econometrica 50, 987-1008.

Erdogdu, E. (2010). Natural gas demand in Turkey. Applied Energy, 87(1), 211-219.

Eltony, M. N. (1996). Demand for natural gas in Kuwait: An empirical analysis using two econometric models. International journal of energy research, 20(11), 957-963.

Estrada, J., \& Fugleberg, O. (1989). Price elasticities of natural gas demand in France and West Germany. The Energy Journal, 10(3), 77-90.

Fang, G., Brooks, J. M., \& Chrischilles, E. A. (2011). Apples and oranges? Interpretations of risk adjustment and instrumental variable estimates of intended treatment effects using observational data. American journal of epidemiology, kwr283.

Gately, D, \& Huntington 2002. The asymmetric effects of changes in price and income on energy and oil demand. The Energy Journal, 23(1), 19-55.

Graham, D. J., \& Glaister, S. (2002). The demand for automobile fuel: a survey of elasticities. Journal of Transport Economics and policy, 36(1), 1-25.

Griffin, J. M. (1979). Energy Conservation in the OECD: 1980 to 2000. Ballinger Publishing Company, Cambridge, MA.

Hendry, D. F., \& Krolzig, H. M. (2005). The properties of automatic gets modelling. The Economic Journal, 115(502), C32-C61.

Hultman, N., Rebois, D., Scholten, M., \& Ramig, C. (2011). The greenhouse impact of unconventional gas for electricity generation. Environmental Research Letters, 6(4), 044008.

Hunt, L. C., \& Evans, J. (Eds.). (2011). International handbook on the economics of energy. Edward Elgar Publishing.

Hunt, L.C., Judge, G., \& Ninomiya, Y. (2003). "Modelling underlying energy demand trends." In: L.C. Hunt, (ed.), Energy in Competitive Market: Essays in Honour of Colin Robinson. Edward Elgar, UK, 140-174.

Ibrahim, I. B., \& Hurst, C. (1990). Estimating energy and oil demand functions: A study of thirteen developing countries. Energy Economics, 12(2), 93-102.

International Energy Association. (2011). World Energy Outlook. Paris: OECD/IEA. 
Kaboudan, M. A., \& Liu, Q. W. (2004). Forecasting quarterly US demand for natural gas. EJ: Inform Technol Econ Manage, 2(1), 1-14.

Khan, M. A. (2015). Modelling and forecasting the demand for natural gas in Pakistan. Renewable and Sustainable Energy Reviews, 49, 1145-1159.

Liu, B. C. (1983). Natural gas price elasticities: variations by region and by sector in the USA. Energy Economics, 5, 195-201.

Lutken, S., Bertule, M., Hansen, J. I., Karavai, M., Sandbukt, S., Staun, F., \& Wieben, E. (2013). Profile of Emissions Reduction Options in Developing Countries. UNEP Ris $\varnothing$ Centre.

Mahadevan, R., \& Asafu-Adjaye, J. (2007). Energy consumption, economic growth and prices: A reassessment using panel VECM for developed and developing countries. Energy Policy, 35(4), 2481-2490.

Marland, G. (2008). Uncertainties in accounting for CO2 from fossil fuels. Journal of Industrial Ecology, 12(2), 136.

Omri, A., Nguyen, D. K., \& Rault, C. (2014). Causal interactions between CO2 emissions, FDI, and economic growth: Evidence from dynamic simultaneous-equation models. Economic Modelling, 42, 382-389.

Pellini, E. (2014). Essays on European Electricity Market Integration.

Ramsey, J.B. (1974). Classical model selection through specification error tests. In: P. Zarembka, (ed.), Frontier of Econometrics. Academic Press, New York, 13-47

Sa'ad, S. (2011). Underlying energy demand trends in South Korean and Indonesian aggregate whole economy and residential sectors. Energy Policy, 39(1), 40-46.

Sambo, A. S. (2005). Renewable energy for rural development: the Nigerian perspective. ISESCO Science and Technology Vision, 1, 12-22.

Shahbaz, M., Lean, H. H., \& Farooq, A. (2013). Natural gas consumption and economic growth in Pakistan. Renewable and Sustainable Energy Reviews, 18, 87-94.

Soldo, B. (2012). Forecasting natural gas consumption. Applied Energy, 92, 26-37.

Sunak, Y., \& Madlener, R. (2011). Residential natural gas demand elasticities in OECD countries: An ARDL bounds testing approach.

Suganthi, L., \& Samuel, A. (2012). Energy models for demand forecasting - A review. Renewable and Sustainable Energy Reviews, 16, 1223-1240

Wadud, Z., Dey, H. S., Kabir, M. A., \& Khan, S. I. (2011). Modeling and forecasting natural gas demand in Bangladesh. Energy Policy, 39(11), 7372-7380. 
Wadud Z, Graham DJ and Noland RB 2010. Gasoline Demand with Heterogeneity in Household Responses. The Energy Journal 31(1), 47-73

Waheed, A., \& Martin, F. (2013). Estimating the Demand Elasticities of Residential Natural Gas in Louisiana. The Global Journal of Finance and Economics, 10(2), 183-189.

Wooldridge, J.M. (2001) Applications of Generalized Method Moments Estimation. Journal of Economic Perspectives 15(4), 87-100. 